\title{
A MÍDIA COMO ESPAÇO FORMATIVO DO SUJEITO ADOLESCENTE
}

\author{
Rosa Maria Bueno Fischer*
}

SIINTESE - Apresentam-se aqui as conclusões de uma pesquisa em que foram analisados dois programas de televisão, um encarte de jornal e uma revista - todos destinados ao público adolescente. A análise, feita a partir de um referencial teónico baseado nos conceitos de sujeito, poder e discurso, da obra de Michel Foucault, permite qualificar a mídia como um "espaço formador de sujeitos", basicamente porque seus discursos e as práticas que instauram constituem um modo especifico de "ser jovem" e se inscrevem numa rede de poder e saber sobre a adolescência, possivel de apreender a partir dos próprios textos.

\begin{abstract}
In this paper are presented the conclusions of a study in which I have analyzed two television programs, a newspaper section and a magazine - all aimed at the teenage public. The investigation was carried out from the theoretical foundation based on the concepts of subject, power and discourse, taken from Michel Foucault's work. It allows us to qualify media as a "formative space of the subject", basically because its discourses and practices constitute specific ways of "being young" and are inserted in a net of power and knowledge about adolescence, which is possible to apprehend from the texts themselves.
\end{abstract}

Sintetizo, no presente artigo, um dos tópicos desenvolvidos na pesquisa que fiz para minha tese de doutorado - Adolescência em discurso: mídia e produção de subjetividade.' Refiro-me ao estatuto "formador" dos meios de comunicação, já que a mídia seria não apenas veiculadora mas sobretudo produtora de saberes especializados - no caso, saberes pertinentes ao mundo dos jovens e adolescentes - colocando-se numa função social nitidamente pedagógica. Os conceitos de verdade e saber aqui utilizados estão diretamente relacionados a outros, como os de sujeito, subjetivação, poder e discurso - todos compreendidos dentro da perspectiva da obra de Michel Foucault, de modo especial os livros $A$ arqueologia do saber e os três volumes de sua História da sexualidade.

$\mathrm{Na}$ esteira dos estudos que se empenham em identificar e articular os diferentes cruzamentos entre sociedade, educação e cultura - como os chamados

- Doutora em Educação pela UFRGS, pesquisadora na Faculdade de Educação da UFRGS e jornalista. E-mail: rosambf@edu.ufrgs.br

1 Tese defendida em setembro de 1996, no Programa de Pós-Graduação em Educação da UFRGS.

\begin{tabular}{|l|l|l|l|l|l|}
\hline VERITAS & Porto Alegre & v. 42 & $\mathrm{n}^{0} 2$ & Junho 1997 & p. 333-348 \\
\hline
\end{tabular}


Estudos Culturais ${ }^{2}$ - as pesquisas que venho realizando, ${ }^{3}$ como esta aqui referida, ocupam-se com a compreensão de um dos aspectos básicos que constituiram e constituem a cultura de nossos tempos: a ação eficaz e profunda dos meios de comunicação de massa na vida cotidiana, especialmente na vida dos mais jovens. Dentro desse campo, meu interesse consiste em descrever os modos pelos quais esta sociedade fala à intimidade dos indivíduos e a seu cotidiano privado através da mídia, propondo-lhes uma espécie de "ação ética" - isto é, oferecendo-lhes, através de inúmeras narrativas de jornais, televisão e revistas, exemplos de como agir sobre si mesmos, de modificar-se, de "formar" a si próprios de uma certa maneira.

Assim, organizo este texto em duas partes principais, com a finalidade de: Idescrever e situar brevemente o material que constituiu o corpus da análise, apresentar as hipóteses e os objetivos da pesquisa, resumir a base teórica a partir da qual foi construído o instrumental de análise, e II - apresentar os principais achados e as conclusões da análise, no que se refere ao que denominei "ethos pedagógico da mídia", ou seja, ao caráter formador assumido pelos meios de comunicação neste final de século, principalmente quando o alvo é o público adolescente.

\section{I - Do objeto e dos objetivos}

A análise considerou quatro produtos da mídia brasileira, destinados ao público adolescente, e veiculados de agosto a dezembro de 1994 - dois programas de televisão: o seriado Confissões de Adolescente, veiculado pela TV Cultura de São Paulo e baseado no diário da atriz Maria Mariana, e o Programa Livre, do SBT, apresentado por Serginho Groisman, e dois materiais impressos: a revista Capricho, da Abril, e o encarte da Folha de S.Paulo, o Folhateen. ${ }^{4} \mathrm{O}$ objetivo foi mostrar como se constitui uma rede de saber e poder sobre a adolescência, exatamente nesse lugar, o lugar do discurso, neste caso, o discurso da mídia, lugar por excelência de produção e circulação de saberes, lugar privilegiado de constituição de sujeitos, neste tempo de cultura globalizada. Todas as evidências indicavam que a mídia dos anos 90 se caracterizava por multiplicar uma infinidade de produtos cujo destino era o público que o mercado convencionou chamar de teen. E essas evidências exigiam uma ruptura, permitida pela análise dos discursos, a partir de um referencial teórico específico.

2 De modo particular os dirigidos por pesquisadores como Raymond Williams, Stuart Hall e Paul Willis, de Birmingham.

3 Minha dissertação de mestrado, publicada sob o título 0 mito na sala de jantar (Porto Alegre: Movimento, 1994, 2a. ed.), analisa o discurso de crianças e adolescentes sobre o caráter mitológico das narrativas de televisão. A tese de doutorado, defendida em 1996 - Adolescência em discurso: midia e produçāo de subjetividade (Porto Alegre: PPGEDU/UFRGS, 1996) - contém uma investigação sobre os discursos da mídia brasileira, dirigidos ao público adolescente. Em diversos artigos, publicados em revistas cientificas, venho fazendo reflexões e análises sobre esse campo em que se cruzam os fenômenos da educação e da comunicação de massa.

4 Analisei na tese os 22 episódios de Confissōes de Adolescente, 57 emissões do Programa Livre, 17 edições do Folhateen e 5 números da revista Capricho, todos veiculados de agosto a dezembro de 1994. 
Procurarei demonstrar aqui que: $1^{2}$ - a partir dos textos é possível apreender os jogos de poder entre diferentes campos discursivos (de modo particular, os campos da medicina, da psicologia, da publicidade e da moda, além é claro do campo específico dos próprios meios de comunicação), campos que disputam a hegemonia na definição do sujeito adolescente, quanto à sua conduta sexual, corporal, moral e à sua definição de gênero, $2^{2}$ - no interior da definição de um certo modo de ser adolescente, a mídia acaba por expor um jogo social de inclusão e exclusão de diferentes adolescências (meninos de rua, jovens trabalhadores, top models, astros do espetáculo, drogados, adolescentes grávidas, meninos e meninas estudantes, atletas, jovens violentados), transformando constantemente os textos referidos a esses grupos, na própria medida das inclusões e exclusões, $3^{\circ}$ - a centralidade insistente da adolescência nos meios de comunicação, sobretudo do corpo feminino adolescente, indica necessariamente - mesmo que de modo tênue e disperso - um movimento de resistência por parte dos mais jovens.

Defendo a hipótese de que a mídia constrói um sujeito adolescente, propondo-lhe uma multiplicidade de normas, regras e "práticas de si" - práticas absolutamente necessárias a um certo tipo de "relação consigo" próprio destes tempos. Os dois conceitos aqui referidos - "práticas de si" e "relação consigo" - foram operacionalizados por Michel Foucault nas análises desenvolvidas em sua História da sexualidade, e podem assim ser entendidos, um em necessária articulação com o outro: a "relação consigo" envolve basicamente uma relação de poder do sujeito sobre si mesmo, e que é exercida através de diferentes "práticas de si", práticas que evidentemente são sempre históricas. Para Foucault, a "relação consigo" é a relação pela qual o sujeito constitui a si mesmo como sujeito moral, ou seja, a relação pela qual ele aprende a reconhecer e a estabelecer para si, como bons e verdadeiros, certos modos de agir e de ser. Isso, por sua vez, exige que o sujeito se submeta a aprendizagens, que ele se exercite e aperfeiçoe segundo valores, regras de conduta e interdições de seu tempo, de sua cultura e de sua condição social e de gênero. Mais ainda: conforme nos mostra Michel Foucault, em nossa cultura o estabelecimento da "verdade de si mesmo", a partir da "relação consigo", atinge necessariamente o problema central da sexualidade do indivíduo e das operações que faz sobre o próprio corpo.

Antes de expor e discutir os resultados da análise, abro um espaço para mostrar como "trabalhei com" Foucauit," operacionalizando os conceitos principais de "sujeito" e de "discurso", a partir das formulações feitas pelo autor ao longo de sua extensa obra.

\section{A - Sujeições do presente}

A pergunta que me faço - sobre a obsessão contemporânea em imiscuir-se naquilo que tem o nome de privado e alçar esse privado ao mundo público e de preferência ao mundo do espetáculo - encontra em Michel Foucault inúmeras ressonâncias. Comecemos pela questão do sujeito. 5er a propósito o capitulo "A paixão de 'trabalhar com' Foucault”, de minha autoria, publicado no
livro Caminhos Investigativos, in: COSTA (Org.). (Ver Biblio.). 
Falar em sujeito, em se tratando de Foucault, é falar de "modos de subjetivação". Modos, isto é, práticas, técnicas, exercícios, num determinado campo institucional e numa dada formação social, pelos quais o sujeito se observa e se reconhece como lugar de saber e de produção de verdade. Foram os gregos que inventaram não só a relação de poder entre homens livres, como a relação de poder do sujeito para consigo mesmo. Colocando a força toda em direção ao "eu", os gregos inventaram a "subjetivação": o melhor era aquele que sabia exercer mais adequadamente o poder sobre si mesmo. Inventava-se ai um modo de existência predominantemente de caráter estético.

Desejoso de conhecer seu presente, Foucault acompanhou as diferentes rupturas nessa trajetória ocidental de voltar-se para si mesmo e descobriu, já nos primeiros anos da Era Cristã, uma transformação naquelas práticas que iam buscando cada vez mais a austeridade e que, com o Cristianismo, afirmavam-se nos atos de autodecifrar-se, confessar-se ao outro, examinar-se e sacrificar-se, atos que permaneciam inspirados na máxima socrática do "conhece-te a ti mesmo". Essa moral entranhou-se no corpo e na alma ocidental, percorreu e percorre os discursos científicos, esquiva-se aqui e ali e reaparece silenciosa nas práticas cotidianas de todos nós. Que restou da cultura clássica de si, que, ao contrário, propunha a idéia de cada um construir, criar a si mesmo como uma verdadeira obra de arte?

Cremos ser possivel, mesmo que modestamente, participar da construção dessa histónia de modos de "relação consigo", situando práticas discursivas e não discursivas de nosso tempo, a respeito da cultura de si, comparativamente às épocas estudadas por Foucault e a momentos marcantes da segunda metade deste século. Mesmo que no final de sua vida Foucault tenha explicitado a importância de lutarmos contra todas as formas de assujeitamento ou de submissão da subjetividade, criando quem sabe formas de sujeição que não submetessem tão radicalmente aquilo que nos é mais caro - a nossa individualidade - ou seja, mesmo que possamos encontrar essa "esperança" em Foucault, é certo que ele estava verdadeiramente preocupado em afirmar algo mais. Para ele, a maior dificuldade dessa luta estaria em considerar a particular forma de poder que nossa sociedade tão bem aprendeu a realizar e que tanto soube aperfeiçoar - um poder preocupado com o bem-estar da população e com a saúde de cada um, um poder que se reveste de bondade e sincera dedicação a toda a comunidade, mas que não tem condições de exercer-se senão munido de toda a informação sobre cada grupo, sobre o que pensam e sentem todos os indivíduos e como estes podem ser melhor dirigidos. Mais: 0 fato de o poder exercer-se sobre homens livres estaria diretamente relacionado com uma tendência ao aperfeiçoamento, burilamento e sofisticação das estratégias de poder, de modo a serem criados dispositivos de poder e saber cada vez mais complexos, nos quais os indivíduos terminam por enredar-se, tomando para si mesmos as próprias ações que lhes cingem a subjetividade.

Foucault nos diz que o poder é produtivo, é positivo, é efeito de conjunto: produz sujeitos, discursos, formas de vida. Como se dá isso? Dá-se em uma palavra pela transformação técnica dos indivíduos. Essa transformação atinge basicamente seus corpos e sexualidade, através de inúmeros dispositivos históricos e 
técnicas - como a da confissão que, em momentos e lugares distintos, poderia configurar-se como a técnica-sintese da imensa vontade de saber do homem.

Toda essa reflexão teórica e histórica oferecida por Foucault (reflexão profundamente encarnada em seu tempo, aliás) faz-nos perguntar se as estratégias do bio-poder de que somos herdeiros - isto é, as estratégias do poder em relação à vida das populações - não se configurariam hoje como uma complexa rede de poder que se manifesta ou que se articula através sobretudo dos meios de comunicação. Pergunto: que tipo de sujeição sucede ao homem contemporâneo, protegido por um sofisticado poder pastoral eletrônico, que lhe orienta o modo de alcançar a própria salvação individual? Arriscaria dizer que o "cuidado de si" dos gregos, sem ter desaparecido, nem no século XVIII nem em nossos dias, teria se transformado no "cuidado de si" através do cuidado pastoral dos outros, de todos, de cada um, através de dispositivos como os da mídia. O investimento sobre si mesmo torna-se o objetivo político de cuidar de todos, da saúde de todos, de sua vida reprodutiva, o que necessariamente significa conhecer e ampliar os saberes sobre corpo e sexualidade, corpo e alimentação, saúde e doença, dietas e exercicios, ampliação de todas as possibilidades de uma vida controlada e, se possível, eterna. Esses novos saberes, construídos e elaborados em nome da vida, certamente se constroem em luta com espaços novos de resistência dos indivíduos e grupos, mas geram continuamente práticas cada vez mais sofisticadas de controle das populações. ${ }^{6}$

Os mecanismos de produção de verdade, na sociedade ocidental, aliam uma profunda vontade de saber (base do discurso científico) e uma obstinada vontade de não-saber. A compulsão de tudo falar não significa que o dito libera simplesmente: a confissão e todas as técnicas de exposição ilimitada de si mesmo, que identificamos nos produtos da mídia, essa confissão, para permanecer desejável e permanente, também produz esquecimentos, desconhecimentos, esquivas. Não confessamos tudo, para que haja sempre o que confessar, e somos incitados a sempre confessar para que os peritos (psicólogos, psicanalistas, ginecologistas, comunicadores alçados a pedagogos) nos digam o que somos e como nos devemos conduzir.

Dito de outro modo, a idéia de "relação consigo", vista por Foucault nos gregos clássicos, historicamente e de uma maneira crescente foi-se afastando da protegida zona do homem livre para entranhar-se nas relações de poder e não cessar de manifestar-se em múltiplos lugares e discursos. Não só as formas de "relação consigo" transmudaram-se em práticas confessionais, em técnicas e exercícios de auto-conhecimento espiritual, em modos de segredar o sexo para não vivê-lo ou em formas de produzir e fazer circular saberes sobre o sujeito. Também os "cuidados consigo", especialmente os que se referem aos cuidados com 0 corpo e à regulação das atividades mais prosaicas do cotidiano, foram reprocessados historicamente: longe de buscarem a "arte da existência", eles foram integrados aos objetivos de controle das populações, desde os fins do século XVIII, e conheceram, em nossos tempos, o auge da sofisticação e da multiplicação. O

Desenvolvo esse tema do "poder pastoral eletrônico" no texto publicado na revista Educação, poder \& subjetividade (Ver Biblio.) 
homem contemporâneo é perseguido pelos ideais de beleza e juventude, de longevidade, quase como uma tortura, da mesma forma que é compelido a falar do sexo e de nele reconhecer sua verdade de sujeito. É em torno de seu corpo, portanto, que se concentram todos os saberes, todos os poderes: é nele que podemos apreender todas as transformações históricas, porque o corpo jamais é estável, é aquilo que muda, cresce, degenera, morre, vibra, oculta-se, ajusta-se, explode no exercício de uma função, como nos diz Foucault: a função de ser disponível ou não às dobras do poder.

\section{$B$ - Sobre o discurso}

O que é básico em Foucault, quanto ao discurso, é que o discurso para ele é uma prática. E uma prática histórica. As coisas ditas estão sempre amarradas às dinâmicas de poder e de saber de um determinado tempo. Prática discursiva, portanto, não se confunde com mera expressão de idéias, pensamento, formulação de frases. $O$ esforço do estudioso do discurso será interrogar a linguagem por ela mesma, sem querer buscar referentes nem fazer interpretações reveladoras de verdades ou de sentidos ocultos. Trata-se, portanto, de fazer o esforço de ficar nos espaços brancos, nos espaços sem promessa, multiplicando as coisas ditas a partir delas mesmas. A idéia é operar sobre os documentos, extrair enunciados, colocando-os em relação uns com os outros, ordenar e identificar elementos, construir unidades arquitetônicas que tentem responder à pergunta: por que isso é dito aqui, deste modo e nesta situação, e não em outro tempo e lugar, e de uma forma diferente?

Enunciados são acontecimentos, dispersões, raridades estreitas e singulares, cuja unidade será construída pelo pesquisador. Diversas posições e formas de subjetividade são captadas, lidas como efeitos de um campo enunciativo, a partir da pergunta sobre o "lugar vazio" do sujeito dos enunciados. Assim, não diremos que os personagens dos textos analisados neste trabalho - Maria Mariana ou Serginho Groisman, por exemplo - seriam sujeitos de suas falas, mas diremos que eles ocupam um lugar vazio, eles podem ser sujeitos de um discurso que emergiu aqui e agora. E o menino ou a menina adolescente que afirmam a "necessidade" de ter este ou aquele modo de ser, mostrar este ou aquele tipo de corpo, eles são assujeitados igualmente por um determinado discurso do qual não são propriamente autores. "Fala-se" uma adolescência, "diz-se" de uma adolescência ou de inúmeras adolescências. Estamos, portanto, falando do sujeito como um efeito discursivo.

Os enunciados, da mesma forma que as posições do sujeito, estão "em relação a". Há uma configuração discursiva, heterogênea, há espaços de trocas entre vários discursos, vários campos discursivos, dependendo dos campos de poder em questão. Essa idéia de que cada enunciado é povoado de tantos outros enunciados, e de que há espaços de correlação entre eles, torna-se crucial quando se analisam discursos como os da mídia, porque hoje praticamente todos os discursos sofrem uma mediação ou um reprocessamento através dos diferentes meios de comunicação. Está em jogo nessa pluridiscursividade do social a luta pela imposição de sentido, a luta entre vários discursos, na conquista de novos sujeitos so- 
ciais. Há que se atentar para o fato de que o discurso não tem apenas um sentido ou uma verdade, mas sobretudo que tem uma história, é objeto de uma luta, e certamente de uma luta politica. O não discursivo - o campo das instituições e das práticas sociais - também faz parte do discurso, na medida em que identifica tipos e niveis de discurso, definindo regras que de algum modo atualiza. A temporalidade dos enunciados refere-se exatamente a isso: a que o discurso está investido em práticas, ele mesmo é uma prática, e a partir dele é possivel identificar não só a unidade arquitetônica em si mas a condição dela como história, como ruptura, enfim, como descontinuidade.

A idéia principal, nesse sentido, é que os fatos humanos são raros, eles não estão instalados na plenitude da razão, há um vazio em torno deles para outros fatos que nosso saber nem imagina, o que é poderia ser diferente, no entanto as coisas parecem tão evidentes aos nossos olhos contemporâneos que às vezes sequer percebemos esse outro modo de ser das coisas e de nós mesmos - diz Paul Veyne, referindo-se à concepção de história em Foucault (Veyne, 1982).

Todo o ordenamento das palavras e das coisas, no corpus considerado, e tọda a suposta harmonização em que muitas vezes ele aparece, precisam ser devolvidos à condição de dispersividade, de multiplicidade, de relação, que há nas coisas ditas. É um esforço de aceitar as unidades e organizações para logo desfazê-las, e construir novas unidades com o propósito de colocar à disposição da comunidade de pesquisadores e da sociedade a descrição dos nossos modos de existência, de produção de sujeitos e de verdade, num determinado campo e em relação a um determinado objeto, no presente que vivemos.

\section{C - Sobre o instrumental de análise}

Deleuze, em seu livro sobre Foucault, nos orienta: ele diz que "os enunciados se parecem com os sonhos, e tudo muda, como num caleidoscópio, segundo um corpus considerado e diagonal que se trace. Mas, por outro lado [...], tudo é real no enunciado, e nele toda realidade se manifesta" (Deleuze, 1981, p. 29).

A partir do conceito de "experiência" em Foucault (1990b, p. 10) - "a correlação, numa cultura, entre campos de saber, tipos de normatividade e formas de subjetividade" - foi possivel descrever de que modo a experiência da "relação consigo" (proposta pela mídia ao adolescente) articula e produz saberes, constituise como relação de poder e está intimamente ligada a modos de subjetivação específicos. Considero não só que os documentos da mídia sugerem e discutem "práticas de si" quanto à vida do adolescente, mas que a própria recepção a esses produtos é uma dessas práticas. E que esse conjunto de práticas configura-se como um verdadeiro "lugar formador" das gerações mais jovens em nossos tempos. Ou seja: o modo de a mídia dirigir-se ao adolescente, apanhando-o exatamente no que lhe é mais íntimo e profundo, a "relação consigo", não só configurase como relação de poder, mas sobretudo indica uma ação claramente de caráter formador, pedagógico, educativo por parte da mídia - no sentido foucaultiano de "constituição de sujeitos" ou simplesmente de "processos de subjetivação". 
O instrumental básico aplicado à descrição dos textos dos quatro produtos da mídia foi construído exatamente em torno do conceito de "relação consigo", apanhado em três dimensões principais: $1^{\mathrm{a}}$ - a relação com o próprio corpo, com a intimidade afetiva e sexual, $2^{\mathrm{a}}$ - a relação com o Outro - a familia, os amigos, os diferentes, os grandes astros e modelos da mídia, os objetos de desejo, $3^{\mathrm{a}}$ - a relação com o mundo, com os limites dados socialmente. A análise situa as coisas ditas em sua materialidade, em relação aos falantes e ao lugar de onde falam, e em relação aos interdiscursos, à memória e à descontinuidade dos discursos.

\section{II - A produção de uma adolescência "normal" e equilibrada}

Em todos esses textos, constrói-se o discurso sobre um adolescente em perigo, cuja imagem de beleza e juventude é desejada quase como valor absoluto, ao mesmo tempo em que se cria a seu respeito uma rede de poder e saber, tecida basicamente em nome da vida. Na mídia, parte-se de uma suposição básica: a de que, na adolescência, tudo deve ser dito. $O$ adolescente não deve confessar sua intimidade apenas a seus pares, mas sobretudo é preciso que se confesse aos mais velhos, aos pais, aos irmãos e principalmente aos médicos. Estes é que são o lugar da segurança, ao mesmo tempo que da incitação ao discurso e da normalização. Sobressai nos textos não só a confissão, mas a resposta do perito. $\mathrm{E}$ isso é mostrado na sua radical contradição. A personagem de Maria Mariana, a irmã mais velha do seriado Confissões, chega a afirmar: "Imaginar que os seus segredos mais secretos cairam nas mãos de um desconhecido, acho pior que morrer". Esse dito, contraditório em relação à própria multiplicação do diário, afirma um tempo em que se aceita morrer, depositando toda a intimidade em público, pois é esse exatamente o modo de ser ou de viver que ora aprendemos.

0 que o adolescente manifesta e confessa é principalmente o conflito em relação à própria normalidade ou anormalidade. Apanhado no testemunho dos leitores de Folhateen ou de Capricho, nos debates do Programa Livre - tal problema é pauta para intermináveis matérias, cujo objetivo é definir para o menino e a menina adolescente um certo lugar numa determinada hierarquia de comportamentos, sentimentos e atitudes. Constatada a anormalidade, a revista, o jornal e a tevê propõem, através de seus especialistas, os procedimentos necessários a um modo normal de ser ou de existir. As dúvidas em geral são sobre as proporções do corpo e sobre desconhecimentos e dúvidas quanto ao relacionamento sexual. "Isso que eu sinto, isso que meu corpo é, isso é normal?" - perguntam insistentemente os adolescentes. E quase sempre as respostas da mídia afirmam: o que os jovens descrevem é perfeitamente normal. Mas o pavor da anormalidade permanece, justamente porque é este o movimento que caracteriza a sociedade disciplinar dos nossos tempos: no interior das instituições e hoje, dos meios de comunicação e das novas tecnologias de informação, estandardizamos diferentes processos de formação dos sujeitos, dirigindo-nos basicamente a eles como individualidades, ao mesmo tempo que eles, nesse processo, tornam-se disponiveis à norma.

Em resposta ao questionamento adolescente sobre "ser ou não ser normal", a mídia acaba por elaborar um discurso que privilegia a harmonia e o equilíbrio, propondo ao público a pauta de uma adolescência ideal. Fazer a "experiência de 
si" - considerando a relação desse público com os meios de comunicação - significa atentar para todas as normas, todos os exercícios, todos os cuidados, na busca do equilíbrio, da medida e principalmente da destruição das contradições. Propõese um modo "politicamente correto" de enfrentamento da vida. Isso está na matenialidade dos textos, nas fotos, nas recomendações de como vestir, dançar, namorar, alimentar-se, dormir. Isso está na construção dos roteiros, na condução dos debates, nas entrevistas e reportagens. Todos os lados são contemplados, todos os excessos são condenados. Isso, como veremos a seguir, tem uma relação direta com o que chamo de "ethos pedagógico da mídia".

\section{A - Campos discursivos em luta}

De dentro dos discursos analisados, apreende-se um jogo de poder que coloca em evidência - ora estrategicamente solidários, ora francamente divergentes campos de saberes e práticas, basicamente da medicina, da psicologia, da publicidade e do marketing que, no espaço da mídia, disputam a hegemonia na definição de modos de existência adolescente, dos problemas que esse grupo enfrenta $e$ das formas desejáveis de resolvê-los.

Assim, na construção da imagem de uma adolescência equilibrada e ideal que, para isso, precisa ser domada, normalizada - quem está autorizado a dizer a palavra verdadeira, a fazer diagnósticos científicos, em princípio são as autoridades da psicologia e da medicina. Todos os enunciados sobre o "sexo seguro" ou sobre o "sexo perigoso", por exemplo - e que correspondem às novas práticas de relacionamento sexual entre jovens, às concepções sobre a perda da virgindade $e$ assim por diante - são respaldados, de um lado, pelo texto da psicóloga ou da psicanalista (em geral são mulheres que falam desse lugar) e, de outro, pela fala do médico especialista (sobretudo o ginecologista homem). Esses discursos são mediados - e quase sempre assumidos - eventualmente pela família e, insistentemente, pelos representantes do próprio campo enunciativo em questão: os profissionais da mídia e os astros que nela circulam.

Algumas tendências, nesse sentido, são apontadas pela análise: a familia, é subordinada à palavra autorizada dos peritos, para gerir a vida de seus adolescentes em risco. A aliança pai/irmã-mais-velha/médico/psicóloga é tanto mais sólida quanto mais se depreciam ou se negam os professores e psicopedagogos. Estes são mostrados bem distantes do lugar da verdade liberal, da boa e consistente informação, da liberalização responsável dos costumes, da afetividade esclarecida, dados por aquela aliança.

Em segundo lugar, a desvalorização da instituição escolar, aliada à ausência da família, coloca em evidência o campo da comunicação de massa não apenas como veiculador de diferentes discursos ou fonte básica de entretenimento das pessoas, mas como lugar por excelência da informação educativa. Formar, ensinar, orientar são ações que transbordam de seus lugares tradicionais, sendo assumidas explicitamente pelos media, através de uma infinidade de modalidades enunciativas, cuja característica principal é a publicização de fatos, pessoas, sentimentos, comportamentos. Meninas e meninos adolescentes, as̀sim, são hoje um "problema" médico que ultrapassa os fóruns tradicionais, problema que se discute, 
prioritariamente, nos meios de comunicação ou, pelo menos, com sua indissociável participação. A privacidade tornada pública constitui-se uma das marcas destes tempos e coloca o campo dos meios de comunicação numa posição bastante privilegiada.

Mas, como vimos aqui, esse discurso - da mídia sobre a adolescência - jamais poderá nem deverá ser visto nessa única relação, e sim na multiplicidade e complexidade de elementos, de outros campos, que ai entram em ação: define-se psicologicamente $o$ adolescente, reafirmando as características de uma idade e, de modo especial, as novas formas de experimentação do sexo e do desejo, a medicina, mais do que nunca, explicita as transformações físicas, a prevenção de doenças, os cuidados estéticos, as regras dos regimes e dietas, as normas familiares não deixam de ser enunciadas, e novos saberes se multiplicam, como o das práticas esportivas e de condicionamento físico, da cosmetologia, da moda, da formação de modelos para a publicidade, e assim por diante. São essas relações que atuam no discurso da mídia sobre a adolescência e a juventude, e somente a partir dos cruzamentos que aí se dão é possivel defini-lo, especialmente quanto à função "formadora" das gerações mais jovens, aqui discutida.

\section{$B$ - $O$ ethos pedagógico da mídia}

Vejamos em que consiste, segundo o material analisado, o caráter "pedagógico" dos meios de comunicação. Na atuação "pedagógica" da mídia com o público, no caso, o público adolescente - isto é, na atuação de seus enunciadores principais, como os animadores de programas e os personagens principais das narrativas de ficção em tevê, os colunistas de revistas e jornais, ou das diversas modalidades de comunicação de cada meio - já não podemos falar de uma relação vertical, de sujeitos falantes, de um lado, e de sujeitos pura e unicamente receptores, de outro. Como nas práticas da pedagogia escolar, o mundo adulto dos meios de comunicação empreende uma sofisticada mediação das relações do público consigo mesmo.

Cada vez mais parece que nos afastamos da idéia de uma juventude transgressora e rebelde, que é substituída por outra, cultuadora do belo corpo, consumista, falante, responsável, esclarecida, equilibrada - qualidades sempre referidas à memória de um discurso feito mito, dos jovens que revolucionaram os costumes e a política, nos anos 60 - como vimos no episódio dos "caras-pintadas". O modo como se dá o enfrentamento das gerações, em função disso, traduz-se na mídia ou pelo elogio adulto de uma juventude livre e não hipócrita ou pela exposição do contraste entre homens e mulheres maduros e liberados, lado a lado com meninos e meninas que alimentam os hábitos e sonhos mais conservadores. De qualquer forma, esses adultos que falam de dentro dos meios de comunicação - quase sempre jornalistas, atores e atrizes, publicitários, músicos e cantores, ou então especialistas da área médica que se transformam em figuras típicas da mídia - fazemno com a autoridade de adultos experientes e como depositários de verdades, de bons exemplos a seguir. Alguns deles, como Maria Mariana, Serginho Groisman, 
Zeca Camargo, Rosely Sayão,' cada um à sua maneira, assumem uma espécie de missão salvadora dos adolescentes e jovens, sem deixarem de manifestar, nessa tarefa, um certo "prazer de saber e de poder", próprio dos que fazem o outro falar.

Num tempo em que grande parte das escolas e das familias apenas começa a acompanhar as transformações sociais, os novos padrões de comportamento sexual e as novas linguagens com que se comunicam os jovens "navegadores" das infovias, os educadores eletrônicos adiantam-se e tomam para si quase uma missão - informar esses milhares de jovens brasileiros, ensinando-os principalmente a se defenderem da doença e da morte, cuja origem é justamente a experimentação e a vivência do sexo. Rompe-se, pelo menos em relação aos educadores da mídia, com a idéia de um adulto que não entende o jovem, de pessoas conservadoras que não sabem interpretar os desejos e os arroubos da juventude. A "ordem" de usar o preservativo aparece no mesmo texto que diz "faça sexo", ou melhor, "faça sexo seguro". Ou seja, uma ordem a que resistimos fala também de liberação: liberação do sexo e do desejo, incitação de um mundo que só quer a nossa felicidade.

O modo como se constroem esses textos conduz a que os "receptores" afirmem ali encontrar acolhida, ali serem ouvidos e respeitados, mais talvez do que em outros espaços e instituições sociais. A imensa vontade de saber, que sustenta a civilização ocidental, principalmente a instituição do discurso científico, tem hoje, portanto, mais um forte aliado: o conjunto de "biopedagogos da mídia".

\section{C-Inclusões e exclusões de adolescências}

Que recortes faz a mídia ao dirigir-se ao amplo público chamado por ela de "alvo teen"? Que recortes nós fazemos ao analisar esse discurso? O adolescente descrito por este estudo é visto em sua concreta condição de classe e gênero, segundo os dois principais objetos de atenção dos textos da mídia - o corpo e a sexualidade jovem. Vejamos, a seguir, alguns tópicos dessas inclusões e exclusões dos adolescentes, sempre relacionadas com as diferentes "técnicas de si", em direção a uma proposta de "relação consigo".

A proliferação de textos e imagens sobre a beleza da mulher jovem não apenas vende um estilo de ser, portar-se e vestir-se, acompanhados do necessário consumo de uma série quase infinita de produtos e das informações detalhadas sobre todos os exercícios e procedimentos técnicos, cuja promessa é a reprodução dos corpos e rostos das top models: opera, principalmente, um modo de subjetivação que associa o imperativo da beleza à atratividade sexual, reduplicando as forças no sentido de um tipo de constituição de gênero que, sabemos, ultrapassa as vivências específicas de apenas uma classe. Os rituais propostos na revista Capricho servem de pauta para o que se publica nas páginas de Folhateen ou para as cenas de Confissões e os debates do Programa Livre: a menina é julgada a partir de seu corpo, das medidas e das proporções de cada parte desse corpo. É

\footnotetext{
Maria Mariana é atriz e autora do diário, da peça de teatro e do seriado Confissōes de Adolescente, Groisman é jornalista e apresentador do Programa Livre, do SBT, Zeca Camargo é jormalista, foi apresentador do programa Matéria-Prima, da TV Cultura de S.Paulo e atualmente é editor do Fantástico, na TV Globo, Rosely Sayão é psicanalista e tem uma coluna ("Sexo") no cademo Folhateen, da Folha de S. Paulo.
} 
incitada permanentemente a fazer o exame de si, para uma desejável e necessária transformação, que movimenta um staff múltiplo: psicólogos, médicos, publicitários, industriais da moda e da cosmética, sem falar no poder motivacional básico, de fazer-se atraente não só para si, mas para "ele" - o menino, o jovem, o homem.

Neste caso, não há cisão entre as figuras estelares da mídia - as modelos famosas e as atrizes de televisão e cinema: todas, meninas comuns e estrelas, devem submeter-se ao sacrifício das operações sobre o próprio corpo, embora a grande violência esteja justamente em que o produto final, visível nas modelos, permaneça distante para a maioria das leitoras e espectadoras, restando-lhes exatamente, mais do que a certeza de um resultado satisfatório, a ocupação permanente com toda uma tecnologia do corpo, que se multiplica em produtos, exercícios e cuidados. A eficácia de tal discurso se traduz na produção e reprodução de uma série de enunciados que enfatizam não só as possibilidades concretas de transformação do corpo (as mais belas mulheres um dia se consideraram "horriveis") mas, de modo particular, a afirmação de que existe uma beleza maior, a beleza interior. Assim, a mídia opera uma forma de inclusão das "adolescentes comuns", ao mesmo tempo que a nega, na figura da grande estrela. Esse é o movimento permanente de seus discursos, que se assemelha ao que Foucault afirma sobre o dispositivo da sexualidade: o movimento simultâneo de saber e não-saber, de incitar e frear. Eu diria: de incluir e excluir, incessantemente.

O tema do desejo, da sexualidade e do prazer vem sempre acompanhado do discurso científico da medicina, de tal forma que a fruição dessa experiência, vivida em seus primeiros arroubos e medos, esconde-se sob uma série de recomendações e cuidados, particularmente para a menina. O ginecologista surge como o perito mais valorizado (e quase sempre temido), absolutamente indispensável na vida da adolescente, mesmo antes de ela menstruar pela primeira vez: em nome da saúde e da defesa de qualquer problema mais grave, como a gravidez e as doenças sexualmente transmissíveis. A menina medicalizada precocemente é a adolescente de classe média que, inclusive, pode até engravidar e cuidar de seu filho, com um certo glamour, apesar de todo o conflito decorrente dessa situação. Quando o tema é a gravidez adolescente ou o aborto, separam-se nitidamente os mundos sociais: para as privilegiadas meninas de classe média, os cuidados médicos e o apoio da familia, para as meninas pobres, o texto busca as estatísticas demográficas, as explicações sociológicas e o testemunho dos mitos e da religiosidade popular. De qualquer forma, em ambos os mundos, o que se ratifica é uma condição feminina de peso e responsabilidade, de solidão inclusive, elementos que se misturam ao mito da sagrada maternidade, "naturalmente" desejada.

Meninos e meninas afirmam a revalorização da virgindade, o romantismo das relações e a espera do momento "certo" e da pessoa "certa", os planos de casamento e de um futuro sem sonhos maiores do que o sucesso e a segurança. Mas depositam nos canais da mídia toda a contradição desse discurso comportado: dúvidas inconcebiveis num tempo de tanta informação, temores que, curiosamente, afastam-se do grande centro de atenções (ADS, gravidez) e que indagam, ad nauseam, sobre possiveis anormalidades, no próprio corpo e nas íntimas vivências sexuais. Mesmo que todos os esclarecimentos sejam dados sobre ser ou não 
ser normal, o tema da normalidade é reincidente e adquire um novo estatuto, quando nomeado no interior dos meios de comunicação. Ali, diferentes processos de "formação" dos sujeitos são propostos como normas e normalidades de ser, numa linguagem que, taticamente, fala ao indivíduo particularizado, único.

Nas diferentes modalidades enunciativas da mídia, estimula-se o sujeito adolescente a aprender todas as formas de confissão da verdade sobre si mesmo esse procedimento que se tornou central, extremamente valorizado em nossa cultura, no conjunto dos procedimentos de individualização, pelo poder (Cf. Foucault, 1990a, p. 58). Pela seleção dos temas de debate e de reportagens, bem como das perguntas feitas pelos leitores e das respostas dos especialistas, pode-se afirmar que 0 alvo dos conselhos e do incitamento à confissão é prioritariamente a menina. Na mesma medida em que é o rosto e o corpo todo feminino que se expõe, através da figura das atrizes e modelos ou da narrativa de histórias de desejo e conflito amoroso, também é em torno da adolescente que se constrói, como dissemos acima, o discurso da medicalização da mulher - calcado justamente no testemunho, incitado, de uma série de afirmações sobre o desconforto, a vergonha e mesmo o desprezo com relação ao próprio corpo, bem como sobre as inseguranças quanto à vivência da sexualidade. O mais difícil de ser dito, a intimidade, é o grande ponto de chegada dos textos da mídia, principalmente quando se trata de falar da menina. Como se ela - e, por extensão, a mulher - colocada em evidência nas últimas décadas, tivesse um poder dificil de ser identificado e, por isso, provocasse a criação, pela sociedade, de variados mecanismos de exposição de uma privacidade misteriosa que, mesmo intensamente exposta, continuamente se esquiva.

A adolescência apanhada e exposta nos textos e imagens de Capricho, Folhateen, Confissões de Adolescente e Programa Livre - mesmo confessando seus temores em relação a uma possivel anormalidade - é descrita como o ponto de referência daquilo que se constituiria uma adolescência padrão, normal, média. Em relação a ela são mostradas outras adolescências bem distintas. De um lado, a dos jovens astros da mídia, da moda e da publicidade; de outro, a legião de múltiplas existências dispersas, quase sempre portadoras de um "mal" ou então francamente "diferentes", a ponto de só parecerem integrar o grande conjunto apresentado pelos meios de comunicação, pelo fato de serem chamadas pelo mesmo nome: teens. Trata-se aqui dos trabalhadores precoces, das meninas grávidas, das mães adolescentes, jovens violentadas sexualmente, portadoras do HIV, jovens sobreviventes de massacres como o da Candelária, adolescentes agredidos e agressores das torcidas de futebol, indios jovens aculturados ou não, atores negros, jovens religiosos, atrizes e políticos jovens.

Essa tensão entre o Eu e esses Outros, tão "diferentes-de-mim", mostra-se na mais simples alusão a uma existência - a mídia parece dizer: 'olhem, eles existem e nós nos abrimos a todas as diferenças' - ou na mais escancarada expressão das dissimetrias sociais neste País, a inclusão do adolescente pobre, nos textos analisados, faz-se pela linguagem da exclusão, da excepcionalidade. Ou ele é notícia de violência e criminalidade, ou ele é convidado a aparecer na mídia apenas em ocasiões muito especiais, quando vem compor o quadro da nítida oposição entre 
dois mundos sociais, que não se reconhecem entre si. Cruzando as categorias de classe e gênero, temos que, nos meios de comunicação - e, de resto, em todas as outras instâncias sociais - há uma duplicação das forças sobre a mulher pobre, de tal forma que, além de aparecer na condição de pobre e portadora do HIV, por exemplo, ela pode ser submetida a um questionamento sobre sua beleza e a possibilidade de, infectada, ser objeto do desejo masculino.

Interpelam-se o menino e a menina, nesses meios, para que venham integrar um mundo de normalidade - 0 que inclui o conhecimento e a aceitação desses diferentes excepcionais (não a identificação com eles) - ao mesmo tempo que se mostra o exemplo e o modelo dos jovens astros da tevê, do cinema e da publicidade, como aqueles que também não se confundem com as pessoas comuns, mas que thes balizam os ideais de beleza e perfeição. As histórias de vida dos novos "deuses do Olimpo" aparecem em oposição ao testemunho de vidas muito simples e sem nenhum encanto espetacular, em geral marcadas pela dor, a doença, a morte e a violência. A excepcionalidade dos jovens "comuns" é justamente a falta, o erro e a conseqüente trajetória de cura e salvação, que também servirão de exemplo para o leitor e o espectador, tanto quanto a história de sucesso, fama, beleza e dinheiro/daqueles que não podem nem devem ser mostrados jamais em sua miséria.

\section{$D$ - Que resistência?}

"Lá onde há poder há resistência", diz Foucault (1990a, p. 91). Em cada imagem analisada, em cada texto organizado e reorganizado inúmeras vezes, fala uma adolescência que se faz disponivel à norma e à docilização dos corpos e da sexualidade, mas que, simultaneamente, mostra-se em suas saliências de resistência exatamente em direção às quais se dirigem os focos da ação dos poderes e saberes interessados nessa população. Assim, quanto mais os adolescentes são produzidos em sua condição de pessoas angustiadas com o fantasma da anormalidade, mais falam de si, mais lêem e ouvem sobre os modos de homens e mulheres conhecerem a si mesmos e decifrarem seus desejos e prazeres. Ora, esse é o ponto de partida para novas práticas e discursividades que, em contrapartida, questionam os mecanismos de controle e vigilância criados nesse processo. Ou seja, a sofisticação das redes de poder é também o aperfeiçoamento das possibilidades de investir sobre si mesmo, talvez para além dos dispositivos de poder e saber.

Ao confessar sua miséria como sujeitos sexualizados e como sujeitos de desejo, meninos e meninas adolescentes participam da grande estratégia de colocação do sexo em discurso, fazendo-o cada vez mais o valor e o segredo maior da cultura, o que exige que constantemente seja vigiado e multiplicado em novos saberes. Da mesma forma, neste fim de século, quando a solução para o grave problema da ADS se reduz a um gesto - o uso do preservativo - é exatamente em tomo dele que se faz a resistência explícita dos adolescentes. Não se trata aqui de julgar essa negação, mas de vê-la em sua positividade também: esse fato faz que se multipliquem as pesquisas, estudos e estatísticas sobre o comportamento sexual dos mais jovens, provoca a criação de grupos inter-institucionais, governamentais ou não, interdisciplinares - todos buscando o apoio dos meios de comuni- 
cação, sobretudo da tevê - fazendo proliferar as minúcias da intimidade adolescente, o testemunho que, a partir da pergunta básica "por que você não usa camisinha?", coloca em evidência o poder curioso dos adultos e uma complexa rede de saberes.

Prazerosos ou violentados, belos ou destruídos, é dos corpos adolescentes que se trata, em cada fragmento desses discursos. Feito animal exótico ou selvagem, há um adolescente, menino ou menina, capturado na ternura de sua perdição, na explosão de seu desejo, na obrigação de ser belo e magro, na radical violência da exclusão social. Dele, diz-se o que pode e o que deve ser dito hoje, nesse lugar que, mesmo afirmando-se aberto às pluralidades e diferenças, continua elegendo um espectador e um leitor médio, ele mesmo, porém, tão múltiplo quanto o é qualquer indivíduo.

\section{Concluindo}

Problematizar o pensamento, para Foucault, significa proceder a uma operação sobre a relação básica entre o saber, o poder e o "si", que pode ser captada e descrita, a partir dos discursos e em sua dispersão. Não busquei, nem em minha pesquisa nem neste artigo, um sentido ou uma verdade dos discursos da mídia sobre a adolescência. Simplesmente, fiz a imersão num momento e numa história especifica, tentando, talvez, apanhar um instante deste presente, que certamente suporta a herança de uma longa história de produção da verdade do sujeito. Organizando os textos segundo o tema das "relações consigo", mostrei o quanto as formas de constranger a si mesmo e operar sobre si incluem também a ação pedagógica e formadora do Outro sobre o "si". Igualmente, vimos que nossa cultura, neste fim de milênio, reescreve toda uma "tecnologia do eu", que mistura resquícios da "ocupação consigo" dos gregos e da "renúncia do eu", aprendida com o Cristianismo, produzindo modos completamente distintos de incitar à confissão e de cercar desejos, prazeres e felicidades.

Enfim, sublinhei aqui um processo específico de subjetivação inventado em nosso tempo: aquele experimentado pelas gerações mais jovens, na sua relação com o consumo de bens culturais produzidos e veiculados por diferentes canais da mídia. Estabeleci uma relação direta entre "processos de subjetivação" e "processo de formação" dos indivíduos, mostrando como a mídia emerge, neste final de século, na condição de lugar privilegiado de constituição do sujeito, particularmente porque se volta, cada vez mais, para inúmeras práticas de "relação consigo", em que o centro das atenções é a vida privada, são os diferentes cuidados com o corpo e a confissão sem limites da intimidade sexual. 


\section{Referências Bibliográficas}

DELEUZE, Gilles. Foucault. São Paulo: Brasiliense, 1991.

FISCHER, Rosa Maria Bueno. "Mídia e produção de subjetividade na cultura contemporânea". Educação, Subjetividade \& Poder. Porto Alegre, v. 3, n² 3, p. 48-58, jan.jun. 96.

— . "A paixão de 'trabalhar com' Foucault". In: COSTA, Marisa (Org.). Caminhos Investigativos. Novos olhares na pesquisa em educação. Porto Alegre: Mediação, 1996.

FOUCAULT, Michel. A arqueologia do saber. Rio de Janeiro: Forense, 1980.

. "El sujeto y el poder". Revista Mexicana de Sociologia, UNAM, México, v. 2, n² 3, jul./set. 1988 , p. 3-20.

. História da sexualidade I: a vontade de saber. Rio de Janeiro: Graal, 1990a.

. História da sexualidade II: o uso dos prazeres. Rio de Janeiro: Graal, 1990b.

. Históna da sexualidade III: o cuidado de si. Rio de Janeiro: Graal, 1985.

VEYNE, Paul. Como se escreve a história: Foucault revoluciona a história. Brasilia: Ed. da UNB, 1982. 